\title{
Car dependency beyond land use: Can a standardized built environment indicator predict car use?
}

\author{
Eva Van Eenoo \\ Cosmopolis Centre for Urban Research- \\ Department of Geography \\ Vrije Universiteit Brussel \\ eva.van.eenoo@vub.be
}

\author{
Kobe Boussauw \\ Cosmopolis Centre for Urban Research- \\ Department of Geography \\ Vrije Universiteit Brussel \\ kobe.boussauw@vub.be
}

\author{
Koos Fransen \\ Cosmopolis Centre for Urban Research- \\ Department of Geography \\ Vrije Universiteit Brussel \\ koos.fransen@vub.be
}

Abstract: In June 2019, the government of the Flemish Region (Belgium) launched the "mobility score," a standardized built environment indicator that informs citizens in Flanders about the walking or cycling accessibility from their dwelling to a range of basic amenities and public transport stops. The development of the mobility score was developed to be a tool to raise awareness of the environmental impact of travel. Against this backdrop, this paper assesses the extent to which the mobility score can predict car use and aims to contribute to the line of research that studies travel patterns in relation to accessibility, spatial context, and travel mode choice. Based on the data from the Flemish Travel Behavior Survey, we analyze the effect of the interaction between the built environment, frequency of car use and vehicle kilometers traveled. Our findings illustrate that frequent and intensive car use is not an exclusive feature of suburban and rural residents in Flanders, or of those who travel long distances. The outcomes show that the mobility score can predict the frequency of car travel but only in the inner city. As for other areas, travel behavior shows little variance among respondents. The presence of a company car in a household is a much stronger predictor of vehicle kilometers traveled than any other variable, including the built environment. Travel behavior turns toward car use once a household acquires a car, almost regardless of the type of neighborhoods where respondents live. In Flanders, policy has so far been directed more toward curbing car use than discouraging car ownership. Our findings suggest that it could be more effective to aim for the latter, as this prevents the development of a cycle of car-oriented behavior in the first place.

\section{$1 \quad$ Introduction}

In June 2019, urban planning, travel behavior and accessibility were at the heart of the public debate in Flanders (Belgium). The reason for this unusual event was the launch of the so-called "mobiscore" by

Copyright 2022 Eva Van Eenoo, Koos Fransen \& Kobe Boussauw

http://dx.doi.org/10.5198/jtlu.2022.2073

ISSN: 1938-7849 | Licensed under the Creative Commons Attribution - Noncommercial License 4.0

The Journal of Transport and Land Use is the official journal of the World Society for Transport and Land Use (WSTLUR) and is published and sponsored by the University of Minnesota Center for Transportation Studies.

\section{Article history:}

Received: August 21, 2021

Received in revised form:

November 22, 2021

Accepted: December 29, 2021

Available online: February 21,

2022 
the Flemish government. The mobiscore is a standardized built environment indicator that aims to raise public awareness of the environmental impact of residential choice. ${ }^{1}$ By the end of 2019, the mobility score was the 13th most googled keyword in Belgium, thus preceding topics such as the football competition and the national election. The mobility score informs citizens in Flanders about the walking or cycling accessibility from their dwelling to a range of basic amenities (schools, shops, services) and public transport stops. Every dwelling's mobility score is publicly available and ranges from 0 to 10 . A high score—close to 10 —indicates outstanding accessibility on foot or by bike, whereas a low score signifies the opposite. Unsurprisingly, this results in high scores for urban environments (over 8.5) and poor scores in rural areas (below 5) (Figure 1). Mobility scores over 9 only occur in the cores of the largest cities (Brussels, Antwerp and Ghent), followed by scores from 8 to 9 in the urban agglomerations and in the cores of smaller cities. Real estate agencies integrated the score on their websites, enabling potential tenants or buyers to objectively compare the rate of accessibility between different dwellings.

The development of the mobility score was primarily devised as an attempt to curb the continuous growth of sprawl and its associated negative effects. According to a report by the European Environment Agency, Belgium is one of the hotspots for urban sprawl in Europe (European Environment Agency, 2016). As such, the mobility score was drawn up as a strategy to motivate households to reduce the environmental impact of travel by choosing their dwelling "wisely." The assumption is that trips from a dwelling with a high mobility score are more likely to have a less adverse impact on the environment than trips originating from a dwelling with a low score. One of the reasons for the overheated debate in the press and on social media was that rural inhabitants felt stigmatized because of their residential choice while blaming urban citizens for their so-called moral superiority. They argued that a lack of public transport and dedicated bicycle infrastructure leaves them no other choice than a car, and moreover, that the low mobility score of their dwelling does not properly reflect their travel behavior. As such, a theoretically neutral standardized built environment indicator such as the mobility score quickly became politicized: the public and some policy makers interpreted the score as a means to provide us with insights on and predictions of travel patterns. The magnitude of the score became equated with the likelihood that sustainable travel would occur, or that modal shift would at least occur in the near future.

This paper aims to examine the extent to which the current travel behavior in Flanders is in line with the travel behavior we would expect based on the mobility score: is the mobility score-as a proxy for the built environment- a good predictor of travel patterns? How successful is the mobility score in explaining the impact of the built environment on car use and can we indeed conclude that the impact of travel on the environment decreases when the mobility score increases?

After articulating some theoretical considerations, the paper introduces the study area. The next part of the paper describes the selected approach for this study, the data and methodology. The remaining section presents the analyses with the main findings of the research and finally addresses the conclusion and discussion.

\section{Effects of the built environment on car dependency}

Urban planning policies are often considered promising in overcoming or mitigating the effects of current car-oriented travel behavior (Banister, 2008). In urban areas, the shorter distances to concentrations of shops and facilities and the availability of public transport (and occasionally cycling infrastructure) provide a favorable setting to travel in a sustainable way, whereas other characteristics, such as conges-

${ }^{1}$ Although the indicator primarily refers to accessibility, we translate the "mobiscore" indicator in the remainder of this paper as "mobility score." 
tion, unsafe travel conditions or limited or expensive parking space, discourage car travel. This mechanism is captured by the notion of the "land-use transport feedback cycle" (Wegener \& Fürst, 2004). Hence, integrated land use and transport planning might induce a modal shift and a reduction in the number of kilometers traveled by car (Ewing \& Cervero, 2010, 2017; Naess, 2012). There is ample evidence that the built environment can indeed influence travel behavior and car ownership, but the lively debate within the field illustrates that there is no agreement on its approximate magnitude, nor on which characteristics of the built environment yield the largest effect (Clifton, 2017; Ewing \& Cervero, 2017; Naess, 2019; Stevens, 2017). Previous research indicated that the explained variance of the built environment is usually low, which means that spatial characteristics explain travel behavior only to a limited extent (Boussauw \& Witlox, 2011; Naess, 2014). That should come as no surprise because the reasons why people travel and how they travel differ and are strongly influenced by, for example, age, gender, income, or employment status (Naess, 2014). Moreover, Fransen et al. (2019) highlighted the importance of an individual's spatio-temporal constraints in relation to travel behavior. Travel behavior is thus very person specific and context related. Nevertheless, and even considering residential self-selection, the mechanism by which people choose their residential location based on their travel preferences and needs, the autonomous influences of built environment characteristics on travel still matter as long as demographic and socio-economic characteristics of the respondents are accounted for (Naess, 2014; Humphreys \& Ahern, 2019). Integrating land use and transport planning can have positive outcomes on traffic safety and on the health and the quality of life of inhabitants of urbanized areas (Nieuwenhuijsen, 2020). Moreover, urban planning can increase the accessibility for those who are hindered from obtaining a driver's license and thus risk missing opportunities to fully participate in society (Fransen et al., 2018). In that sense, urban planning can assist in reducing the number of people who have no other mode choice than a car. Scholars have described this lack of choice as "car dependency" (Jeekel, 2013; Jones, 2011; Stradling, 2007; Wiersma et al., 2016; Wiersma, 2020). In this strand of research, car dependency is defined from the point of view of accessibility, as a feature of the built environment and in relation to transport systems. Based on a set of predefined variables, standardized built environment indicators enable us to map the regions that are car-dependent (Silva \& Pinho, 2010; Wiersma et al., 2016). However, it is widely contented that car dependency reaches beyond aspects of the built environment. For instance, we can distinguish a psychological approach on car dependency that directs its attention to aspects of status of the car and attitudes towards transport modes, emphasizing the sociopsychological benefits that come with car driving (Steg, 2005) and scrutinizing the role of choice and habit (Anable, 2005; Handy et al., 2005). For Flanders, our study area, the experiment of Storme et al. (2020) illustrates that, despite respondents being highly motivated, and despite financial incentives that support switching to alternative travel modes, only few of them managed to omit car use in their daily lives. This example illustrates how our lives and lifestyles became increasingly car dependent. Sociologists refer to this as the lock-in of the car system, highlighting the importance of long-term patterns, structures, and feedback cycles (Dennis \& Urry, 2009; Urry, 2004). In a similar vein, social practice theory argues for an approach which does not focus on the behavior of individuals, but rather puts practices central as units of analysis (Shove et al., 2012). As Watson (2012) and Cairns et al. (2014) argue, this focal shift away from individual travel behavior potentially leads to identifying policy interventions that can contribute to reducing car dependence but are currently not considered. Mattioli et al. (2020) provide a profound insight into the political economy of the car-dependent transport system, uncovering constituents, processes, and characteristics. In summary, and regardless of the considered approach or research field, when discussing car dependency, we identify strong path dependency as a common denominator. 


\section{Study area}

The research area is the Flemish region, part of Belgium. Belgium is a federal state, divided into three regions: the Flemish Region (Flanders) in the north, the Walloon Region (Wallonia) in the south, and the Brussels-Capital Region. In 2019, the Flemish region had approximately 6.6 million inhabitants, and an average population density of 484 inhabitants $/ \mathrm{km}^{2}$ (Statistiek Vlaanderen, 2020). The metropolitan areas of Antwerp (500,000 inhabitants) and Ghent (250,000 inhabitants) are located in Flanders, as are ten regional cities (with a population of around 100,000 inhabitants) and a series of smaller urban centers and municipalities. The Brussels Capital Region, which is the largest agglomeration in Belgium with over one million inhabitants, is geographically situated in the center of Flanders, although it is not administratively part of it.

As mentioned, Belgium is heavily sprawled. This is the result of a historical and political process, which has its roots in the 19th century. Specific policy choices combined with prosperous financial-economic growth enabled a preferred model of living: in the countryside, in a detached house with a private garden (De Decker, 2011). Additionally, a deficient spatial policy and a lack of strong planning instruments led to a pattern of small cores, ribbon development and a dispersed "nebula" of housing, jobs and amenities that are often located in the periphery at car-oriented locations (De Vos, 2015; Verbeek et al., 2014). This self-reinforcing process is associated with ever-increasing mutual distances between homes, jobs, and daily facilities (Boussauw \& Witlox, 2011; Mustafa \& Teller, 2020), and reproduces and strengthens car dependency over time.

Regarding modal split, $62.91 \%$ of all trips in Flanders are conducted by car, and vehicle kilometers traveled increased by 6\% between 2007 and 2016 (Statistiek Vlaanderen, 2018). For trips between 1 and $2 \mathrm{~km}, 56 \%$ travel by car, and this percentage increases to $73 \%$ for trips up to $5 \mathrm{~km}$. $77.65 \%$ of the total amount of kilometers are traveled by car (Reumers et al., 2017). The car fleet is continuously expanding, with an increase of 25.8\% between 2000 and 2019 (Statbel, 2020). Recently, the pace of the increase declined — from $1.5 \%$ yearly to $1.2 \%$ yearly-but nevertheless, car ownership in Flanders remains substantial with 529 cars per 1000 inhabitants, which is slightly higher than the average in the European Union (Statistiek Vlaanderen, 2018). These figures illustrate that a large number of inhabitants of the Flemish region organize their lives around their car.

\section{$4 \quad$ Data and methods}

\subsection{Measuring car use}

This study aims to contribute to the line of research that studies travel patterns in relation to accessibility, spatial context, and mode choice. We focus on car use in relation to the mobility score. We consider the mobility score as a standardized environmental indicator that informs us on the degree of car dependency, which we define as a feature of the built environment. We model car use in a twofold way: vehicle kilometers traveled (VKT), and frequency of car use. Building on Wiersma et al. (2016), who distinguish three temporal levels of car dependency (never needing a car; occasionally needing a car; needing a car daily) we adopt a similar approach and differentiate between daily, weekly and monthly car use.

\subsection{Data}

We used two data sources: one focusing on travel behavior and the other on built environment characteristics. The first dataset is the Travel Behavior Survey for Flanders (TBS), commissioned by the Flemish government (Janssens et al., 2018; Reumers et al., 2016; Reumers et al., 2017). The survey focused 
on vehicle ownership, registered journeys, distances, travel modes and travel frequencies, and collected demographic characteristics of the respondents and their households. In addition, home addresses of the respondents were recorded. The respondents were randomly selected from the Belgian national register. To obtain a larger dataset, we merged the samples of the methodologically comparable surveys of 2015, 2016 and 2017. The collection of the data from these surveys was conducted in exactly the same way and all three datasets have a similar sample size. Merging the samples enabled us to classify respondents based on the residential location while maintaining a sufficiently large number in each subgroup. As expected, we obtained a better model fit for the consolidated dataset than for each dataset separately. We excluded respondents younger than 18 (as 18 is the minimum age to acquire a driver's license in Belgium) and only included respondents who possess a driver's license and have at least one car in the household ( $\mathrm{n}=2920$ ). Although people without a driver's license can be equally car-dependent (Kim, 2011; Siren \& Hakamies-Blomqvist, 2006; Shirgaokar et al., 2020), we consider car-passengers a separate group and therefore did not include them in our analysis. The travel behavior surveys were carried out by Hasselt University between January 2015 and January 2017 by means of a questionnaire and an interview with each respondent.

The second dataset is the GIS-database linked to the mobility score research report (Van Den Bergh et al., 2018), which enabled us to assign a mobility score to the dwelling of each respondent of the TBS. The score combines two main sets of indicators. The first set of indicators are the node and place values for the whole territory of Flanders (Verachtert et al., 2016). Node and place values indicate an area's degree of accessibility (Bertolini, 1999). The node value refers to public transport accessibility: the number of destinations in a certain area accessible within a certain time frame. The place value concerns activities and amenities: the number and type of amenities accessible in a certain area. The second set of indicators comprises the reported travel behavior to amenities and services, derived from the travel diary from the TBS (Reumers et al., 2017). The mobility score is determined by a calculation of the expected average environmental impact of the journeys from a specific dwelling, with both mode and traveled distance considered.

The reader may notice that the mobility score is based on the calculation of the node and place value, but also on the reported travel behavior (distance and mode) to amenities and services, derived from the travel diaries that are included in the TBS. This raises concerns regarding endogeneity because the TBS was used to check whether the mobility score has an impact on travel behavior. Therefore, we conducted our analysis both with the mobility score and subsequently with the underlying node-place value (which does not account for TBS data) as independent variables to test for sensitivity. Both analyses yielded very similar results. For this reason, and because the mobility score (unlike the node and place value) is used as a tool to communicate towards a broad audience, we decided to proceed with the mobility score. 


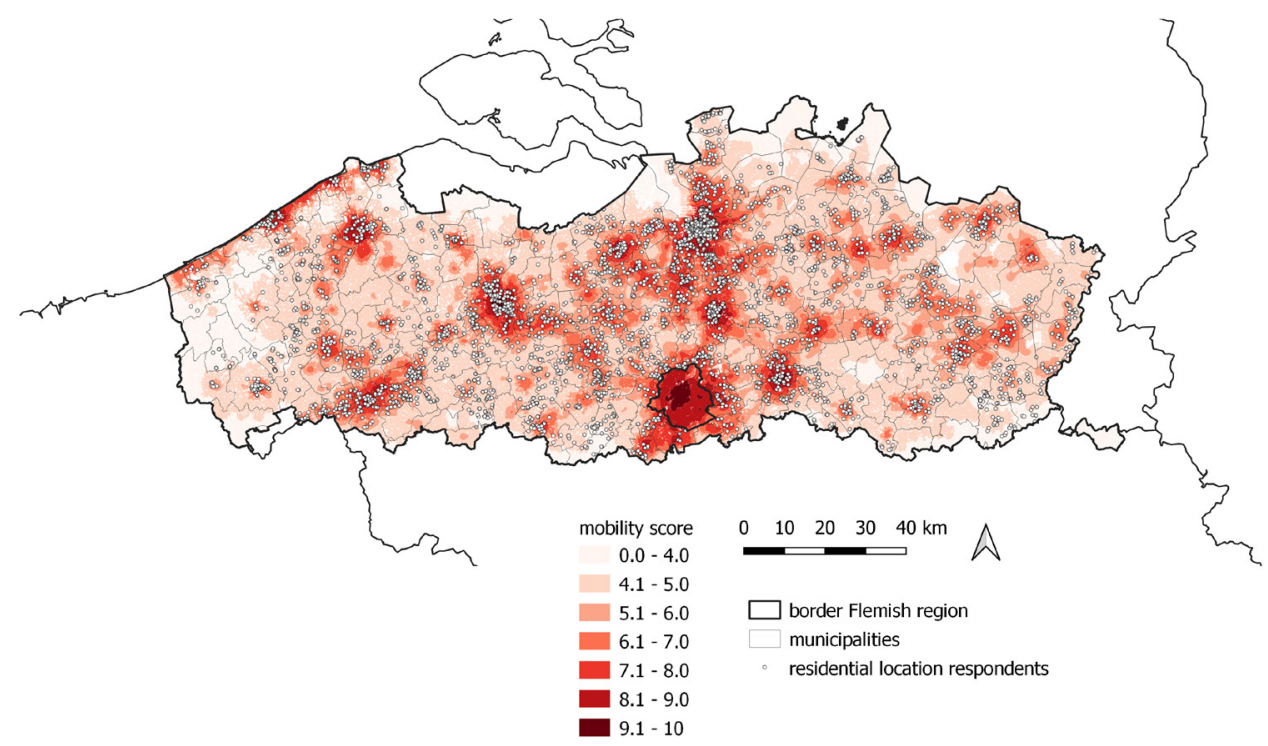

Figure 1. Residential location of the respondents and distribution of mobility scores in the study area (after Van Den Bergh et al., 2018)

\subsection{Variables}

Our main goal is to assess the extent to which the mobility score predicts car use. Do theoretically carindependent areas lead to less car travel and vice versa? As outlined in the previous section, we considered car use as having two components and this led us to consider two dependent variables: (1) frequency of car use and (2) vehicle kilometers traveled (VKT) in two separate regression models (see part 5). In the analysis, the mobility score is treated as the independent explanatory variable.

\section{$5 \quad$ Analysis}

\subsection{Descriptive analysis}

All analyses were carried out in SPSS (version 26). We introduce the samples and provide some descriptive statistics before proceeding to the tests. Table 1 gives an overview of the distribution of mobility scores across our selected sample versus all the respondents of the TBS older than 18. Approximately one third of the respondents of the TBS live in a dwelling with a mobility score over 8 , and almost one third live in a dwelling with a very low accessibility to amenities and public transport (mobility score < 6). Compared to the population, a lower proportion of the subset has very high mobility scores (9.1-10), which already suggests an association between car ownership, driver's license, and the built environment. 
Table 1. Overview of mobility scores of the residence and socio-economic characteristics of the respondents (based on Reumers et al., 2016; Reumers et al., 2017; Janssens et al., 2018)

\begin{tabular}{|c|c|c|c|c|}
\hline & \multicolumn{2}{|c|}{$\begin{array}{l}\text { Respondents with driver's license } \\
\text { and car in household } \\
(\mathrm{n}=2920)\end{array}$} & \multicolumn{2}{|c|}{$\begin{array}{c}\text { Respondents }>\text { age } 18 \\
(n=3864)\end{array}$} \\
\hline & $\mathrm{n}$ & proportion (\%) & $\mathrm{n}$ & proportion (\%) \\
\hline \multicolumn{5}{|l|}{ Mobility scores } \\
\hline$<5.0$ & 430 & 14.7 & 526 & 13.6 \\
\hline $5.0-6.1$ & 474 & 16.2 & 593 & 15.4 \\
\hline $6.1-7.0$ & 628 & 21.5 & 797 & 20.6 \\
\hline $7.1-8.0$ & 594 & 20.3 & 763 & 19.8 \\
\hline $8.1-9.0$ & 525 & 18.0 & 723 & 18.7 \\
\hline $9.1-10.0$ & 268 & 9.2 & 461 & 11.9 \\
\hline \multicolumn{5}{|l|}{ Age } \\
\hline $18-25$ years & 218 & 7.5 & 502 & 13.0 \\
\hline $26-45$ years & 936 & 32.1 & 1107 & 28.6 \\
\hline $46-65$ years & 912 & 31.2 & 1029 & 26.6 \\
\hline $66-75$ years & 601 & 20.6 & 747 & 19.3 \\
\hline$>75$ years & 253 & 8.7 & 479 & 12.4 \\
\hline \multicolumn{5}{|l|}{ Gender } \\
\hline male & 1547 & 53.0 & 1894 & 49.0 \\
\hline female & 1373 & 47.0 & 1970 & 51.0 \\
\hline \multicolumn{5}{|l|}{ Monthly net income } \\
\hline$€ 0-1000$ & 336 & 12.5 & 563 & 16.5 \\
\hline$€ 1001-1500$ & 856 & 31.8 & 1227 & 36.0 \\
\hline$€ 1501-2000$ & 917 & 34.0 & 998 & 29.2 \\
\hline$€ 2001-2500$ & 326 & 12.1 & 348 & 10.3 \\
\hline$€ 2501-3000$ & 145 & 5.4 & 158 & 4.6 \\
\hline$€>3000$ & 114 & 4.2 & 118 & 3.5 \\
\hline \multicolumn{5}{|l|}{ Household composition } \\
\hline single and no children & 282 & 9.7 & 528 & 13.7 \\
\hline single-parent family & 116 & 4.0 & 162 & 4.2 \\
\hline couple and no children & 1092 & 37.4 & 1286 & 33.3 \\
\hline two-parent family & 1105 & 37.8 & 1199 & 31.0 \\
\hline adult living with one parent & 62 & 2.1 & 132 & 3.4 \\
\hline adult living with two parents & 193 & 6.6 & 405 & 10.5 \\
\hline other & 70 & 2.4 & 101 & 3.9 \\
\hline \multicolumn{5}{|l|}{ Paid employment } \\
\hline yes & 1766 & 60.5 & 1948 & 51.1 \\
\hline no & 1154 & 39.5 & 1861 & 48.9 \\
\hline
\end{tabular}


Respondents with driver's license

and car in household

$(\mathbf{n}=2920)$

n

proportion (\%)

Number of cars/adult

no car

$<1$ car

one car

$>$ two cars or more

Company car

yes

311

2605

2920

/

1497

1152

270

40

126

2646

monthly or less

Frequency use of bus

daily

weekly

monthly or less

Frequency use of bicycle

daily

weekly

364

766

1682

/

44.1

48.9

7.0

10.7

89.3

100.0

/

monthly or less
3132

693

81.9

18.1

$503-13.0$

1623

42.0

1482

38.4

5.5

346

10.3

3014

89.7

$\begin{array}{cccc}25 & 0.9 & 121 & 3.1 \\ 148 & 5.3 & 379 & 9.8 \\ 2639 & 93.8 & 3364 & 87.1\end{array}$

In addition, Table 1 shows that age groups $26-45$ and $46-65$ and men are more prevalent in the selected sample. The overview further indicates that income and household composition are positively associated with car ownership, as was to be expected from previous research. The variable that deviates most from the population is employment status, probably indicating the importance of a car for commuting. More than half of the respondents (51.3\%) in our selected sample drive a car daily. Also worth noting is the small share of respondents who use their car only on a monthly basis, supporting 
the hypothesis that once people own a car, they tend to use it for a considerable amount of journeys and evolve towards a car-dependent lifestyle (Cullinane \& Cullinane, 2003; Nolan, 2010; Van Acker \& Witlox, 2010).

\subsection{Group differences}

To determine whether there are significant group differences between frequency of car use and mobility score, we ran a chi squared test of independence. According to the outcome of the test $(\mathrm{p}=0.00)$, there is indeed an association between car dependency and mobility score, although the estimated strength of the association is small (Cramer's $\mathrm{V}=0.10$ ).

Subsequently, we conducted a post hoc test with standardized adjusted residuals. A residual is the difference between the expected frequency in case of no association between car use frequency and mobility score and the observed frequency in each cell of the crosstab (Table 2). The larger the residual, the further the observed frequency deviates from its expected value. According to Agresti and Franklin (2014), adjusted residuals greater than 2 or 3 account for significant deviation from independence. Mobility scores under 5 show a residual over 2 for daily motorists, while mobility scores over 8 show negative residuals below -2 . Solely mobility scores below 5 and over 8 contribute to the significance of the chi squared test. This might lead us to conclude that characteristics of the built environment are associated with car use only for the most urbanized areas and the most remote areas. For the remaining mobility scores, our calculation indicates no significant association.

Table 2. Results of a chi squared test of independence; observed percentages and adjusted residuals

\begin{tabular}{lccc}
\hline & \multicolumn{3}{c}{ Percentages \& adjusted residuals } \\
\cline { 2 - 4 } & Daily use & Weekly use & Monthly or less \\
\cline { 2 - 4 }$<5$ & 60.0 & 33.0 & 7.0 \\
& $(3.9)$ & $(-3.0)$ & $(-1.8)$ \\
\hline \multirow{2}{*}{$<5-6$} & 51.5 & 41.6 & 7.0 \\
& $(0.1)$ & $(1.0)$ & $(-1.9)$ \\
\hline \multirow{2}{*}{$6,1-7$} & 53.0 & 38.4 & 8.6 \\
& $(1.0)$ & $(-0.6)$ & $(-0.6)$ \\
\hline \multirow{2}{*}{$7.1-8$} & 53.9 & 38.7 & 7.4 \\
& $(1.4)$ & $(-0.4)$ & $(-1.7)$ \\
\hline \multirow{2}{*}{$8.1-9$} & 45.5 & 42.3 & 12.2 \\
& $(-2.9)$ & $(1.5)$ & $(2.6)$ \\
\hline \multirow{2}{*}{$9.1-10$} & 38.4 & 44.8 & 16.8 \\
& $(-4.4)$ & $(1.9)$ & $(4.5)$ \\
\hline
\end{tabular}

Adjusted residuals appear between parentheses below observed percentages.

The mobility score is a standardized built environment indicator. Consequently, this analysis does not take into account socio-economic variables. However, as indicated in the literature review, the journeys people make are strongly influenced by socio-economic characteristics of the household. Therefore, in order to confirm whether the mobility score still has an impact on car use when controlling for socioeconomic variables, we will run a multinomial regression, which we present in the next part. 


\subsection{Regression results}

\subsubsection{Frequency of car use: Multinomial regression}

We defined three possible discrete outcomes for the dependent variable "frequency of car use:" daily use of a car, weekly use of a car and monthly (or less) use of a car. For the selection of independent variables, we draw on the extensive body of literature that studied the relationship between car use, the built environment, and socio-economic variables. The question of which role car ownership plays in relation to travel behavior is a very pertinent one, especially since there is evidence of direct and indirect effects on car use, and hence on car dependency. Once people own a car, they tend to use it more often (Kitamura, 2009; Nolan, 2010) and households that own several cars are likely to use their cars more (Dieleman et al., 2002; Van Acker \& Witlox, 2010). Nolan (2010) suggested that there is a strong degree of habit or persistence in households' car ownership decisions — once a car, always a car-which indicates that the car dependency of households can increase over time. The purchase of a car does indeed have a very strong transformative effect on individuals' travel behavior (Mattioli et al., 2020). For this reason, we added "number of cars per household member" as a control variable. We also controlled for the presence of a company car. A company car is defined here as a car made available to an employee by his/her company that may also be used for private purposes. In Belgium, company cars are used by employers as a partly tax-exempt component of the remuneration package they offer to their staff, and are therefore often called "salary car" (May et al., 2019). In addition to the company car, employees often receive a fuel card from their employer, a fringe benefit enabling them to fill up at lower or no cost. Company cars annually cover much longer distances than private cars on average in Belgium. For instance, it is estimated that the commuting distance for employees with a company car is twice the distance of employees without one (May et al., 2019). The variable "company car" is included as a binary variable. Because there is ample evidence of the positive linear relationship between higher income, car use and car ownership (for an overview: Nolan, 2010; Zhang et al., 2014), we included monthly net income as a categorical variable. Furthermore, we added information on the household composition, as car ownership among singles is lower than in households with children (Potoglou \& Kanaroglou, 2008). This is possibly induced by the relative inflexibility caused by time and space constrained child-related trips and activities, which limit the possibility to avoid rush-hours (Oakil et al., 2016). Dargay (2007) found that car ownership increases with age but tends to decrease beyond the age of 50. Gender is also considered to be an important variable (Van Acker \& Witlox, 2010). Finally, we added variables regarding frequency of travel by train, bus, tram, and bike. We added the use of public transport and the bicycle as explanatory variables, as the use of these modes might have an impact on the frequency of use of cars. We found no evidence of multicollinearity between the selected variables, as assessed by tolerance values greater than 0.1 .

When we include the mobility score as a sole explanatory variable, results are statistically significant, but yield extremely low pseudo R Squares (Nagelkerke R Square: 0.02; McFadden: 0.01). When we include all socio-economic variables, pseudo R Squares increase to 0.40 (Nagelkerke R Square) and 0.22 (McFadden), pointing out that the control variables added a substantial amount of explanatory power. All respondents are more likely to travel daily than weekly or monthly compared to the reference group with the highest mobility score. For example, the odds of daily driving compared to weekly driving for respondents living in areas with a mobility score $<5$ is $2.3(1 / 0.43)$ compared to a respondent living in an area with a score over 9. Considering monthly driving, the odds increase towards 4.5 (1/0.22). However, variance among the odds ratios of mobility scores between $<5$ and 9 are minor. This suggests that, once a household has acquired a car, the impact of the built environment only persists in the inner city, being the areas with the highest mobility score. This raises the question whether policy should primarily aim 
at discouraging car ownership, or should instead attempt to increase the share of residential areas with a high mobility score—or combine both strategies.

Table 3. Coefficients of the logistic regression analysis

\begin{tabular}{|c|c|c|c|c|}
\hline \multirow[b]{2}{*}{ (ref.: daily car use) } & \multicolumn{2}{|c|}{ Weekly } & \multicolumn{2}{|c|}{ Monthly or less } \\
\hline & p-value & $\operatorname{Exp}(\mathrm{B})$ & p-value & $\operatorname{Exp}(B)$ \\
\hline$<5$ & $0.00^{* *}$ & 0.43 & $0.00^{* *}$ & 0.22 \\
\hline $5-6$ & $0.00^{* *}$ & 0.54 & $0.00^{* *}$ & 0.22 \\
\hline $6.1-7$ & $0.00^{* *}$ & 0.56 & $0.00^{* *}$ & 0.27 \\
\hline $7.1-8$ & $0.00^{* *}$ & 0.52 & $0.00^{* *}$ & 0.27 \\
\hline $8.1-9$ & $0.02^{*}$ & 0.62 & $0.00^{* *}$ & 0.39 \\
\hline \multicolumn{5}{|l|}{$9.1-10$ (ref.) } \\
\hline \multicolumn{5}{|l|}{ Cars per adult in the household } \\
\hline$<1$ & $0.00^{* *}$ & 2.14 & $0.00^{* *}$ & 18.46 \\
\hline 1 & $0.04^{*}$ & 1.58 & 0.15 & 3.05 \\
\hline \multicolumn{5}{|l|}{$>1$ (ref.) } \\
\hline \multicolumn{5}{|l|}{ Company car } \\
\hline no & $0.05^{*}$ & 1.43 & 0.82 & 1.09 \\
\hline \multicolumn{5}{|l|}{ yes (ref.) } \\
\hline \multicolumn{5}{|l|}{ Age } \\
\hline $18-25$ & 0.75 & 1.10 & $0.00^{* *}$ & 0.07 \\
\hline \multicolumn{5}{|l|}{$26-45$ (ref.) } \\
\hline $46-65$ & $0.00^{* *}$ & 3.41 & $0.00^{* *}$ & 8.45 \\
\hline $66-75$ & $0.00^{* *}$ & 1.77 & $0.00^{* *}$ & 2.51 \\
\hline$>75$ & $0.00^{* *}$ & 1.98 & $0.00^{* *}$ & 3.06 \\
\hline \multicolumn{5}{|l|}{ Gender } \\
\hline male & 0.06 & 0.82 & $0.00^{* *}$ & 0.31 \\
\hline \multicolumn{5}{|l|}{ female (ref.) } \\
\hline \multicolumn{5}{|l|}{ Household composition } \\
\hline single and no children & 0.17 & 1.28 & 0.10 & 1.96 \\
\hline single-parent family & 0.57 & 0.86 & 0.63 & 1.32 \\
\hline adult living with one parent & 0.22 & 1.63 & $0.01^{*}$ & 7.58 \\
\hline adult living with two parents & 0.82 & 0.94 & 0.06 & 2.65 \\
\hline couple and no children & 0.06 & 1.28 & 0.21 & 1.36 \\
\hline \multicolumn{5}{|l|}{ two-parent family (ref.) } \\
\hline \multicolumn{5}{|l|}{ Paid employment } \\
\hline yes & $0.00^{* *}$ & 0.38 & $0.00^{* *}$ & 0.34 \\
\hline
\end{tabular}




\begin{tabular}{|c|c|c|c|c|}
\hline \multirow[b]{2}{*}{ (ref.: daily car use) } & \multicolumn{2}{|c|}{ Weekly } & \multicolumn{2}{|c|}{ Monthly or less } \\
\hline & $\mathrm{p}$-value & $\operatorname{Exp}(B)$ & p-value & $\operatorname{Exp}(B)$ \\
\hline \multicolumn{5}{|c|}{ Monthly net income (in euro) } \\
\hline $0-1000$ & 0.06 & 4.42 & $0.00^{* *}$ & 2.48 \\
\hline $1001-1500$ & $0.03^{*}$ & 1.31 & $0.00^{* *}$ & 1.91 \\
\hline \multicolumn{5}{|l|}{$1501-2000$ (ref.) } \\
\hline $2001-2500$ & 0.42 & 0.81 & 0.29 & 1.79 \\
\hline $2501-3000$ & 0.13 & 0.77 & 0.88 & 1.05 \\
\hline$>3000$ & 0.38 & 0.82 & 0.84 & 0.90 \\
\hline \multicolumn{5}{|l|}{ Frequency use bus } \\
\hline daily & $0.02^{*}$ & 0.20 & $0.03^{*}$ & 0.10 \\
\hline weekly & 0.29 & 0.45 & 0.18 & 0.33 \\
\hline \multicolumn{5}{|l|}{ monthly or less (ref.) } \\
\hline \multicolumn{5}{|l|}{ Frequency use train } \\
\hline daily & 0.10 & 0.48 & $0.00^{* *}$ & 0.08 \\
\hline weekly & 0.07 & 2.52 & 0.44 & 0.30 \\
\hline \multicolumn{5}{|l|}{ monthly or less (ref.) } \\
\hline \multicolumn{5}{|l|}{ Frequency use bike } \\
\hline daily & $0.00^{* *}$ & 0.11 & $0.00^{* *}$ & 0.08 \\
\hline weekly & $0.00^{* *}$ & 0.20 & $0.00^{* *}$ & 0.08 \\
\hline \multicolumn{5}{|l|}{ monthly or less (ref.) } \\
\hline Nagelkerke R Square & 0.40 & & & \\
\hline McFadden & 0.22 & & & \\
\hline
\end{tabular}

The number of cars per adult member in the household clearly has an effect on the frequency of car use. Respondents from households with one car or less per adult household member are more likely to travel less frequently compared to respondents with more than one car per adult household member. This is probably due to the absence of car competition between the members of the households. In one car households, the use of the car can be more restricted, while in households with a car available for each adult family member, there is no such constraint. Furthermore, the frequency of car use is hardly explained by income, except for the lowest income groups (below $€ 1500$ ). From the threshold of more than 1500 euro/month, frequency of car use remains more or less equal among the different income groups. Employment status and consequently, the likelihood that people commute by car, affects car use as well, and so does age. This confirms previous findings that car use tends to decrease around the age of 50. The effect of household composition is negligible. Finally, the frequency with which people use other modes of transport is negatively associated with the frequency with which they drive a car. For those who drive a car weekly, the odds of riding their bike daily versus monthly is 9 (1/0.11). According to the analysis, we can cautiously conclude that the bike is primarily capable of substituting trips by car, although bus and train do play a (minor) role. This can be important for policy measures aimed at reducing car travel. 


\subsubsection{Vehicle kilometers traveled}

As mentioned in the introduction, the mobility score was developed with the aim of reducing the environmental impact of travel, and hence reducing the vehicle kilometers travelled by motorized transport. For this reason, we decided to conduct an analysis with "vehicle kilometers traveled" (VKT) as the dependent variable. Does a high mobility score lead to less vehicle kilometers traveled?

In this part we present the results of the multivariate linear regression with vehicle kilometers traveled as the dependent variable, mobility score as the explanatory variable, complemented with a range of socio-economic control variables. Extremely long travel distances (VKT over 70,000 km/year) were considered as outliers $(\mathrm{n}=12)$ and were consequently removed.

Table 4. Coefficients of the regression analysis

\begin{tabular}{lcccc}
\hline & p-value & Unstandardized B & Standard Error & Standardized B \\
\hline$<5$ & $0.02^{*}$ & 1742.22 & 732.24 & 0.06 \\
$5-6$ & 0.10 & 1172.79 & 719.43 & 0.04 \\
$6.1-7$ & 0.20 & 867.44 & 682.66 & 0.04 \\
$7.1-8$ & 0.11 & 1118.14 & 692.73 & 0.04 \\
$8.1-9$ & 0.61 & -355.54 & 696.13 & -0.01 \\
$9.1-10$ (ref.) & & & &
\end{tabular}

Cars per adult in the household

$<1$

$\begin{array}{llll}0.31 & 421.05 & 413.39 & 0.02\end{array}$

1 (ref.)

$>1$

0.15

1064.49

740.42

0.03

Company car

no (ref.)

yes

$0.00^{* *}$

11874.76

587.76

0.35

Age

18-25

0.16

$-1404.34$

1005.87

$-0.03$

26-45 (ref.)

46-65

66-75

$0.00^{* *}$

$-1834.01$

448.29

$-0.08$

$>75$

$0.00^{* *}$

$-3116.83$

709.84

$-0.12$

$0.00^{* *}$

$-7217.04$

868.45

$-0.20$

Gender

male (ref.)

female

$0.00^{* *}$

$-1199.60$

368.57

$-0.06$

Household composition

single and no children

$0.02^{*}$

$-1562.36$

651.50

$-0.05$

single-parent family

0.74

$-295.53$

897.09

$-0.01$ 


\begin{tabular}{lcccc}
\hline & $\mathrm{p}$-value & Unstandardized B & Standard Error & Standardized B \\
\hline adult living with one parent & 0.19 & -1920.39 & 1436.28 & -0.02 \\
adult living with two parents & 0.70 & -389.44 & 995.08 & -0.01 \\
couple and no children (ref.) & 0.95 & 26.62 & 463.71 & 0.00 \\
two-parent family (ref.) & & & & \\
& & & & -0.03 \\
Paid employment & & & & \\
yes (ref.) & 0.31 & -611.30 & 606.56 & -0.01 \\
no & & & & 0.04 \\
Monthly net income (in euro) & & & & \\
0-1000 & 0.72 & -240.20 & 665.77 & \\
$1001-1500$ & $0.03^{*}$ & -945.82 & 443.15 & 0.05 \\
$1501-2000$ (ref.) & & & & 0.04 \\
2001-2500 & $0.01^{*}$ & 1528.80 & 567.58 & 0.10 \\
$2501-3000$ & $0.03^{*}$ & 1699.27 & 799.26 & 873.05 \\
$>3000$ & $0.00^{* *}$ & 4759.42 & & \\
\end{tabular}

Frequency use car

Daily (ref.)

Weekly

$0.00^{* *} \quad-2605.27$

406.87

$-0.12$

monthly or less

$0.00^{*}$

$-3096.39$

695.72

$-0.09$

Frequency use bus

Daily (ref.)

weekly

0.74

725.82

2163.92

0.02

monthly or less

0.54

1249.79

2042.81

0.03

Frequency use train

Daily (ref.)

Weekly

monthly or less

$\begin{array}{llll}0.86 & -307.22 & 1698.65 & -0.01 \\ 0.68 & 613.32 & 1478.65 & 0.01\end{array}$

Frequency use bike

Daily (ref.)

$0.33 \quad 576.18$

593.90

$-0.03$

weekly

0.33

576.18

593.90

$-0.03$

monthly or less

0.14

836.37

559.26

0.04

R Square 0.34

${ }^{*} \mathrm{p}<0.05^{* *} \mathrm{p}<0.01$

Respondents living in a dwelling with a mobility score under 5 represent more VKT compared to respondents with a mobility score over 9 . This corresponds with findings of previous research: respon- 
dents living in areas with a low node and place value are expected to cover longer distances to reach a number of amenities (Boussauw et al., 2011). Nevertheless, this only holds for mobility scores under 5 , as the analysis shows no significant differences in VKT between the other mobility score categories. Moreover, standardized beta coefficients for mobility scores are low, so the power of the mobility score in explaining VKT is rather limited. Frequency of car use, company car, age and income are much stronger predictors than mobility score. Notably, the variable "company car" stands out. The outcome of the regression confirms that beneficiaries of a company car drive significantly more. Owners of a company car, and respondents with higher incomes, are responsible for more VKT than low-income groups and respondents without a company car. VKT tends to decrease as age increases. Women travel less kilometers by car, but the difference to men is very small. We found no significant effects of household composition and employment status. The impact of other modes on VKT is negligible. Whereas our first regression demonstrated that the more respondents ride a bike, the less they drive a car, the use of the bike or public transport has no effect on VKT according to the linear regression. This may raise concerns over the ability of other modes to replace the car for longer distances and effectively reduce emissions.

The $\mathrm{R}^{2}$ indicates that $34 \%$ of the observed variance in distance traveled can be explained by the model. If we redo the regression analysis on the basis of solely the mobility score, we obtain a significant result with a nevertheless negligible $\mathrm{R}^{2}$ equating to 0.01 . However, using only "company car" as a control variable, the $\mathrm{R}^{2}$ is, in line with what was to be expected considering that the variable "company car" shows the largest standardized beta coefficient, remarkably high: 0.20 . This means that the presence of a company car in a household is a much stronger predictor of VKT than any other variable in the regression, including the built environment. Policies that aim at reducing VKT in Flanders are expected to be more successful when tackling the company car system than when motivating people to live in a dwelling with a high mobility score.

\section{Discussion and conclusion}

This research was designed to determine the effect of the built environment on car use by means of the mobility score, a standardized built environment indicator. The outcomes show that the mobility score does affect frequency of car use. Nevertheless, our findings suggest that the effect is weak and that once below the threshold of 9, the mobility score no longer has an impact on the frequency of car travel. When assessing VKT, we only note significant effects when considering mobility scores lower than 5 and higher than 9. Regarding the scores between 5.1 and 9, travel patterns are very similar between categories of respondents, although they may live in very different areas when it comes to characteristics of the built environment.

Our findings demonstrate that frequency of car use and VKT decrease with age. This might indicate that older respondents rely more on destinations in the vicinity of the dwelling. Respondents with lower incomes travel significantly less frequently and cover fewer kilometers by car, even when controlling for their mobility score. In the public debate on the mobility score in Flanders, one of the recurrent comments was that the mobility score would not properly reflect actual travel behavior. Based on the analysis, we can indeed conclude that a standardized built environment indicator is not able to capture the diversity in travel patterns among different age and income groups. From the threshold of 1500 euro/month, the frequency of car use is no longer explained by income, although income is a fairly strong predictor of VKT. Households with moderate incomes can drive as frequently as households with a higher income, but their destinations are generally located closer to their dwellings. A similar conclusion concerns gender: males and females tend to travel by car with more or less the same frequency, but males cover longer distances. 
We cannot make solid predictions about travel patterns solely based on the mobility score. In that sense, the mobility score does not entirely meet the expectations set by the Flemish government. This is because the mobility score is a standardized indicator, unable to capture personal features and structural constraints. For example, the calculation of the mobility score does not take into account where and when household members of a particular dwelling carry out their daily activities, or which and how many vehicles they possess. Moreover, the mobility score neglects the strength and the far-reaching effect of the car-dependent system in people's daily household organization.

The discussion of the mobility score has illustrated that a complex concept as car dependency cannot be captured by a standardized built environment indicator alone. Nevertheless, there are some good reasons to develop standardized environmental indicators. Firstly, regarding policy, the indicator informs the government about suitable locations for new or additional developments, and pinpoints which areas are worth densifying and diversifying and which ones are not. This is the reason why the node-place value analyses were conducted in the first place. Secondly, we could interpret the mobility score as a "resilience score." The data of the TBS report the actual travel behavior. However, if we consider potential travel behavior, the neighborhoods with high mobility scores illustrate the type of built environment that is a precondition for moving towards a less car-dependent society. Neighborhoods with low mobility scores are less well prepared to make the transition to a post-carbon transport system. For the residents themselves, the advantage of a high mobility score is abundantly clear. If one day, for some reason, it is no longer feasible for some to acquire or to drive a car, families living in a home that is characterized by a high mobility score will fare better than the families in remote areas. In communicating the mobility score to the public, it might be wiser to highlight these aspects than to focus on the expected less tangible environmental benefits (which are, as our research illustrated, very limited anyway). In that sense, the role of urban planning lies primarily in shaping the built environment in such a way that certain travel preferences can easily be materialized by a wide range of people, as to contribute to breaking the cycle of car dependency (Handy, 2017; Wiersma, 2020).

In line with other research, our study highlighted the importance of socio-economic characteristics in travel behavior research, characteristics in which transport policy can hardly intervene. Nevertheless, what emerged from this study is the importance of car ownership when discussing car dependency. Our findings indicate that, once a household acquires a car, and especially in households with more than one car per adult household member, travel patterns are oriented towards car use, almost regardless of the type of neighborhoods respondents live in, except for the inner city. In Belgium, policy has so far been more directed towards curbing car use than discouraging car ownership. Our findings suggest that it could be more effective to aim for the latter, as this prevents the development of car- oriented habits in the first place. Municipalities could start experimenting with car-free neighborhoods when (re)developing areas with high mobility scores. Moreover, with respect to communication about the mobility score, the stress could be put more clearly on the possible consequences of going to live in a neighborhood with a high mobility score: new residents should be aware that parking one or more cars in front of their dwelling will not be obvious. Consequently, such areas would more readily be presented as neighborhoods where car use is the exception rather than the rule. Further research could identify in more detail which factors play a critical role in the decision to buy and hold on to a car, primarily in urban areas, and to assess to what extent the car is a necessary attribute for the organization of life. When it comes to decreasing VKT, the most promising direction is to intervene in the current beneficial system of company cars for employees.

Regarding potential long-term effects of COVID-19 on car travel and car dependency, we do not expect any significant changes in results with a dataset that would be collected after the pandemic. Although people became more familiar with place-independent work and teleworking, this does not necessarily lead to less car travel or less VKT because of the presence of constant time travel budgets (Van 
Wee \& Witlox, 2021).

Overall, our findings illustrate that frequent and intensive car use is not an exclusive feature of suburban and rural residents, neither an exclusive feature of those who need to travel long distances. Although the built environment is a necessary condition to enable sustainable transport, it is far from sufficient to break the cycle of car dependency. By solely focusing on the role of the built environment, we risk simplifying and ignoring the complex and institutionalized drivers behind car dependency. 


\section{References}

Agresti, A., \& Franklin, C. (2014). Statistics: The art of learning from data (3rd ed.). Harlow, England: Pearson.

Anable, J. (2005). Complacent car addicts or aspiring environmentalists? Identifying travel behavior segments using attitude theory. Transport Policy, 12(1), 65-78.

Banister, D. (2008). The sustainable mobility paradigm. Transport Policy, 15(2), 73-80.

Bertolini, L. (1999), Spatial development patterns and public transport: The application of an analytical model in the Netherlands. Planning Practice \& Research, 14(2), 199-210.

Boussauw K., \& Witlox F. (2011). Linking expected mobility production to sustainable residential location planning: Some evidence from Flanders. Journal of Transport Geography, 19(4), 936-942.

Cairns, S., Harmer, C., Hopkin, J., \& Skippon, S. (2014). Sociological perspectives on travel and mobilities: A review. Transportation Research Part A: Policy and Practice, 63, 107-117.

Clifton, K. J. (2017). Getting from here to there: Comment on "does compact development make people drive less?” Journal of the American Planning Association, 83(2), 148-151.

Cullinane, S., \& Cullinane, K. (2003). Car dependence in a public transport dominated city: Evidence from Hong Kong. Transportation Research Part D: Transport and Environment, 8, 129-138.

Dargay, J.M., (2007). The effect of prices and income on car travel in the UK. Transportation ResearchPart A, 41, 949-960.

De Decker, P. (2011). Understanding housing sprawl: The case of Flanders, Belgium. Environment and Planning A: Economy and Space, 43(7), 1634-1654.

De Vos, J. (2015). The influence of land use and mobility policy on travel behavior: A comparative case study of Flanders and the Netherlands. Journal of Transport and Land Use, 8(1), 171.

Dennis, K., \& Urry, J. (2009). After the car. Cambridge, England: Polity Press.

Dieleman, F. M., Dijst, M., \& Burghouwt, G. (2002). Urban form and travel behaviour: Micro

level household attributes and residential context. Urban Studies, 39(3), 507-527.

European Environment Agency. (2016). Urban sprawl in Europe (Joint EEA-FOEN report, EEA Report No 11/2016). Copenhagan: European Environment Agency.

Ewing, R., \& Cervero, R. (2010). Travel and the built environment: A meta-analysis. Journal of the American Planning Association, 76(3), 265-294.

Ewing, R., \& Cervero, R. (2017). Does compact development make people drive less? The answer is yes. Journal of the American Planning Association, 83(1), 19-25.

Fransen, K., Deruyter, G., \& De Maeyer, P. (2018). The impact of driver's license ownership on unemployed job seekers' access to job openings: Assessing the driver's license at School project in Flanders. Case Studies on Transport Policy, 6(4), 695-705.

Fransen, K., \& Farber, S. (2019). Using person-based accessibility measures to assess the equity of transport systems. In Measuring transport equity (pp. 57-72). Amsterdam: Elsevier.

Handy, S. (2017). Thoughts on the meaning of Mark Stevens's meta-analysis. Journal of the American Planning Association, 83(1), 26-28.

Handy, S., Weston, L., \& Mokhtarian, P. L. (2005). Driving by choice or necessity? Transportation Research Part A: Policy and Practice, 39(2-3), 183-203.

Humphreys, J., \& Ahern, A. (2019). Is travel based residential self-selection a significant influence in modal choice and household location decisions? Transport Policy, 75, 150-160.

Janssens, D., Declercq, K., \& Wets, G. (2018). Onderzoek Verplaatsingsgedrag Vlaanderen, 5.2 (20172018). Hasselt, Belgium: Instituut voor Mobiliteit.

Jeekel, H. (2013). The car-dependent society. A European perspective. Surrey, England: Ashgate. 
Jones, P. (2011), Conceptualising car 'Dependence.' In K. Lucas, E. Blumenberg \& R. Weinberger (Eds.), Auto motives. Understanding car use behaviours (pp. 39-62). Bingley, UK: Emerald.

Kim, S. (2011). Assessing mobility in an aging society: Personal and built environment factors associated with older people's subjective transportation deficiency in the US. Transportation Research Part F: Traffic Psychology and Behavior, 14(5), 422-429.

Kitamura, R. (2009). A dynamic model system of household car ownership, trip generation, and modal split: Model development and simulation experiment. Transportation, 36, 711-732.

Mattioli, G., Roberts, C., Steinberger, J. K., \& Brown, A. (2020). The political economy of car dependence: A systems of provision approach. Energy Research \& Social Science, 66, 101486.

May, X., Ermans, T., \& Hooftman, N. (2019). Company cars: Identifying the problems and challenges of a tax system. Brussels Studies [En ligne], Notes de synthèse, $n^{\circ} 133$, mis en ligne le 25 mars 2019, consulted on May 30, 2020.

Mustafa A., \& Teller J. (2020), Self-reinforcing processes governing urban sprawl in Belgium: Evidence over six decades. Sustainability 2020, 12(10), 4097.

Naess, P. (2012). Urban form and travel behavior: Experience from a Nordic context. Journal of Transport and Land Use, 5(2), 21-45.

Naess, P. (2014). Tempest in a teapot: The exaggerated problem of transport-related residential selfselection as a source of error in empirical studies. Journal of Transport and Land Use, 7(3), 57-79.

Næss, P. (2019). Meta-analyses of built environment effects on travel: No new platinum standard. Journal of Planning Education and Research, 0739456X1985642.

Nieuwenhuijsen, M. J. (2020). Urban and transport planning pathways to carbon neutral, livable and healthy cities: A review of the current evidence. Environment International, 140, 105661.

Nolan, A. (2010). A dynamic analysis of household car ownership. Transportation Research Part A: Policy and Practice, 44(6), 446-455.

Oakil, A. T. M., Manting, D., \& Nijland, H. (2016). Determinants of car ownership among young households in the Netherlands: The role of urbanization and demographic and economic characteristics. Journal of Transport Geography, 51, 229-235.

Potoglou, D., \& Kanaroglou, P. S. (2008). Modelling car ownership in urban areas: A case study of Hamilton, Canada. Journal of Transport Geography, 16(1), 42-54.

Reumers, S., Polders, E., Janssens, D., Declercq, K., \& Wets, G. (2016). Onderzoek Verplaatsingsgedrag Vlaanderen 5.2 (2015-2016). Hasselt, Belgium: Instituut voor Mobiliteit.

Reumers, S., Declercq, K., Janssens, D., \& Wets, G. (2017). Onderzoek Verplaatsingsgedrag Vlaanderen 5.2 (2016-2017). Hasselt, Belgium: Instituut voor Mobiliteit.

Silva, C., \& Pinho, P. (2010). The structural accessibility layer (SAL): Revealing how urban structure constrains travel choice. Environment and Planning A, 42, 2735-2752.

Siren, A., \& Hakamies-Blomqvist, L. (2006). Does gendered driving create gendered mobility? Community-related mobility in Finnish women and men aged 65+. Transportation Research Part F: Traffic Psychology and Behavior, 9(5), 374-382.

Shirgaokar, M., Dobbs, B., Anderson, L., \& Hussey, E. (2020). Do rural older adults take fewer trips than their urban counterparts for lack of a ride? Journal of Transport Geography, 87, 102819.

Shove, E., Pantzar, M., \& Watson, M. (2012). The dynamics of social practice: Everyday life and how it changes. Thousand Oaks, CA: SAGE.

Statbel. (2020). Voertuigenpark. Retrieved from https://statbel.fgov.be/nl/themas/mobiliteit/verkeer/ voertuigenpark\#panel-13

Statistiek Vlaanderen. (2018). Aantal personenwagens in Vlaanderen gestegen tot ruim 3,5 miljoen. Retrieved from https://www.statistiekvlaanderen.be/personenwagenpark-0 
Steg, L. (2005). Car use: Lust and must. Instrumental, symbolic and affective motives for car use. Transportation Research Part A: Policy and Practice, 39(2-3), 147-162.

Stevens, M. (2017). Does compact development make people drive less? Journal of the American Planning Association, 83(1), 7-18.

Storme, T., De Vos, J., De Paepe, L., \& Witlox, F. (2020). Limitations to the car-substitution effect of MaaS. Findings from a Belgian pilot study. Transportation Research Part A: Policy and Practice, 131, 196-205.

Stradling, S. (2007). Determinants of car dependence. In T. Gärling \& L. Steg (Eds.), Threats to the quality of urban life from car traffic: Problems, causes and solutions. Oxford: Elsevier.

Urry, J. (2004). The 'system' of automobility. Theory, Culture \& Society, 21(4-5), 25-39.

Van Acker, V., \& Witlox, F. (2010). Car ownership as a mediating variable in car travel behavior research using a structural equation modelling approach to identify its dual relationship. Journal of Transport Geography, 18(1), 65-74.

Van Den Bergh, G., Aeltermans, S., Mouton, V. \& Engels, D. (2018). Verkenning en ontwikkeling Mobiscore. Brussels: Eindrapport Departement Omgeving Vlaanderen.

van Wee, B., \& Witlox, F. (2021). COVID-19 and its long-term effects on activity participation and travel behavior: A multiperspective view. Journal of Transport Geography, 95, 103144.

Verbeek, T., Boussauw, K., \& Pisman, A. (2014). Presence and trends of linear sprawl: Explaining ribbon development in the north of Belgium. Landscape and Urban Planning, 128, 48-59.

Verachtert, E., Mayeres, I., Poelmans, L., Van der Meulen, M., Vanhulsel, M., Engelen, G. (2016). Ontwikkelingskansen op basis van knooppuntwaarde en nabijheid voorzieningen, eindrapport. Brussels, Belgium: Department Omgeving Vlaanderen.

Watson, M. (2012). How theories of practice can inform transition to a decarbonized transport system. Journal of Transport Geography, 24, 488-496.

Wegener, M., \& Fürst, F. (2004). Land-use transport interaction: State of the art (SSRN scholarly paper ID 1434678). Amsterdam: Social Science Research Network.

Wiersma, J., Bertolini, L., \& Straatemeier, T. (2016). How does the spatial context shape conditions for car dependency? An analysis of the differences between and within regions in the Netherlands. The Journal of Transport and Land Use, 9(3), 33-55.

Wiersma, J. K. (2020). Commuting patterns and car dependency in urban regions. Journal of Transport Geography, 84, 102700.

Zhang, J., Yu, B., \& Chikaraishi, M. (2014). Interdependences between household residential and car ownership behavior: A life history analysis. Journal of Transport Geography, 34, 165-174. 